must be taken with the latter technique to avoid radioisotope accumulation in the bladder urine that can obscure visualization of the pubic bone.

CT and MRI scans have been used for the differential diagnosis of a variety of lesions of the pubis symphysis such as fractures, osteolysis, osteomyelitis and dislocations. Vogelzang et al. ${ }^{11}$ described a case of tuberculous osteomyelitis of the pubis in which CT scan showed irregular destruc-

\section{References}

1. Del Busto, R., Quinn, E.L., Fisher, E.J. \& Madhaven, T. Osteomyelitis of the pubis symphysis. JAMA 1982, 248: 1498-1500.

2. Sequeira, W., Jones, E., Seigel, M., Lorenz, M. \& Kallick, C. Pyogenic infections of the pubis symphysis. Ann Intern Med 1982, 96: 604-606.

3. Burns, J.R. \& Gregory, J.G. Osteomyelitis of the pubis symphysis after urological surgery. J Urol 1977, 118: 800-805.

4. Evans, T.W., Evely, R.S. \& Morcos, S.K. Asymptomatic osteomyelitis of the symphysis pubis. Postgrad Med J 1985, 61: $267-268$.

5. Kido, D., Bryan, D. \& Halpern, M. Haematogenous osteomyelitis in drug addicts. Am J Roentgenol 1973, 118: 356-363.

6. Rutherford, A. Osteomyelitis of the symphysis pubis. $N Z$ Med J 1983, 96: 322-333.

7. Keats, T.E. An Atlas of Normal Roentgen Variants that may Simulate Disease, 2nd ed. Yearbook Medical Publishers, Chicago, 1979, p. 196. tion and erosion of the pubic bone with a soft tissue mass. Plain X-ray had earlier failed to demonstrate the lesion. Manzaneque et al. ${ }^{12}$ also described the use of CT scan to diagnose tuberculous osteomyelitis of the pubic symphysis. Turner et al. ${ }^{13}$ found MRI to be particularly useful in the differential diagnosis of pain in the pubic symphysis in a patient with chloroma.

8. Steinbach, H.L., Patrakis, N.L., Gilfillan, R.S. \& Smith, D.R. The pathogenesis of osteitis pubis. J Urol 1955, 74: 840-846.

9. Rosenthal, R.E., Spickard, W.A., Markham, R.D. \& Rhamy, R.K. Osteomyelitis of the symphysis pubis. J Bone Joint Surg 1982, 64-A: 123-128.

10. Nixon, G.W. Haematogenous osteomyelitis of metaphysealequivalent locations. Am J Roentgenol 1978, 130: 123-129.

11. Vogelzang, R.L., Hendrix, R.W. \& Neiman, H.L. Computed tomography of tuberculous osteomyelitis of the pubis. $J$ Comput Assist Tomogr 1983, 7: 914-915.

12. Manzaneque, L., Martin, I., Garcia-Bragado, F., Beiztegui, A., Dastis, C. \& Sanchez-Matas, P. Osteoarticular tuberculosis of the symphysis pubis presenting as a hypogastric cystic mass in a woman with primary Sjogrens syndrome. $\mathrm{Br} J$ Rheumatol 1992, 31: 495-496.

13. Turner, R.M., Wallace, W.P. \& Prietto, C. MR of soft tissue chloroma in a patient presenting with left pubic pain and hip pain. J Comput Assist Tomogr 1991, 15: 700-702.

\title{
Spontaneous rupture of the spleen in association with idiopathic thrombocytopaenic purpura
}

\author{
M.C. Winslet, M.J. Webberley, V. Melikian ${ }^{1}$ and I.A. Donovan
}

Department of Surgery and ${ }^{1}$ Medicine, Dudley Road Hospital, Dudley Road, Birmingham B18 7QH, UK

Summary: Spontaneous rupture of the spleen is rare and has not been previously reported in association with idiopathic thrombocytopaenic purpura. Its rarity makes familiarity with its presentation difficult and may result in a potentially fatal delay in diagnosis and treatment.

\section{Introduction}

Rupture of a histologically normal spleen usually occurs as a result of indirect trauma or iatrogenic injury. Rarely, in association with well-documented pathological changes, the spleen may

Correspondence: M.C. Winslet, M.S., F.R.C.S., University Department of Surgery, Royal Free Hospital, Pond Street, London NW3 2QG, UK.

Accepted: 4 February 1993 spontaneously rupture. Spontaneous rupture of a histologically normal spleen is exceedingly rare and its association with idiopathic thrombocytopaenic purpura has not been previously reported.

\section{Case report}

A 24 year old male with congenital aortic valve disease and idiopathic thrombocytopaenic purpura 
had agreed to be a subject for the clinical section of the Royal College of Physicians Membership examination.

He had asymptomatic mixed aortic valve with predominant stenosis, and during previous investigation he had been found to have persistent thrombocytopaenia $\left(70-84 \times 10^{9} / 1\right)$ with increased megakaryoctyes on bone marrow, and a negative antinuclear factor. There was no clinical or ultrasonographic evidence of hepatosplenomegaly.

During the examination, following abdominal palpation by four candidates, the patient complained of sudden onset light headedness with epigastric and left shoulder pain. On examination he was pale with a pulse of 80 beats/minute, a blood pressure of $80 / 40 \mathrm{mmHg}$ and good peripheral perfusion. A previously documented mild systolic and diastolic murmur was noted. Examination of the abdomen revealed epigastric tenderness only with scanty bowel sounds. Investigation revealed a haemoglobin of $12.2 \mathrm{~g} / 1$, white cell count of $11.2 \times 10^{6} / 1$ and a platelet count of $6.7 \times 10^{9} / 1$. Urea and electrolyte and serum amylase estimation was normal. Chest and abdominal radiographs and a 12-lead electrocardiogram were unremarkable. A differential diagnosis of critical aortic stenosis, possible aortic dissection or occult intra-abdominal pathology was considered. The patient was treated with intravenous fluids with a corresponding improvement in systolic pressure to $100 \mathrm{mmHg}$. Within half an hour the patient had a second hypotensive episode without tachycardia but was noted to have a changing systolic murmur with increasing abdominal distension. An emergency echocardiogram was normal. Abdominal paracentesis revealed a haemoperitoneum and the patient was transferred to theatre for an emergency laparotomy. Repeat preoperative haemoglobin estimation had fallen to $5.2 \mathrm{~g} / \mathrm{l}$. At laparotomy $2.5 \mathrm{dm}^{3}$ of fresh blood and clot was evacuated from the peritoneal cavity. The spleen was slightly enlarged with a cortical rupture which had burst through the splenic capsule. There was no evidence of adhesions. An emergency splenectomy was performed and the patient was given a pneumococcal vaccine (Pneumovax R). Postoperative recovery was uneventful and the patient was discharged one week later on penicillin V $250 \mathrm{mg}$ twice daily with persistent thrombocytopaenia. Subsequent Paul Bunnell test and routine virology screen was negative. Histological examination of the spleen was unremarkable apart from mild red pulp hypertrophy.

\section{Discussion}

Spontaneous rupture of the spleen is rare and is almost always associated with underlying splenic pathology. The most common association is with infectious mononucleosis, ${ }^{1,2}$ although it may also be associated with portal hypertension and infective endocarditis. ${ }^{3,4}$ An association with idiopathic thrombocytopaenia purpura has not been previously reported.

Spontaneous rupture of a histologically normal spleen is an exceedingly rare phenomenon. It was first described by Atkinson in $1874^{5}$ and subsequently comprehensively reviewed by Orloff and Peskin in $1958 .^{6}$ The authors suggested four diagnostic criteria; no history of trauma; no evidence of pre-existing splenic disease; no perisplenic adhesions suggestive of previous trauma and a normal spleen on macroscopic and histological examination. The aetiology of this condition remains obscure. It may occur secondary to the presence of intraperitoneal adhesions, even in the absence of preceding abdominal trauma. ${ }^{7-9}$ Several other aetiology factors have been proposed: it is possible that one area of the spleen alone is diseased which becomes undetectable after rupture. In certain cases an abnormally mobile spleen may rupture secondary to intermittent torsion. Splenic vein spasm or congestion secondary to portal hypertension may also occur. ${ }^{10-13}$ Rupture of a degenerative or aneurysmal splenic artery produces a similar clinical picture but at laparotomy the spleen should be intact.

Iatrogenic splenic trauma is not an infrequent occurrence and may have been contributory in this case. It most commonly occurs during laparotomy, but has also been reported in association with cardiac massage ${ }^{14}$ thoracocentesis ${ }^{15,16}$ and colonoscopy. ${ }^{17}$ It is possible that repeated abdominal examination may have contributed to the eventual rupture of this macroscopically and histologically normal spleen. Such a possibility highlights the need for gentle palpation during all abdominal examinations and emphasizes the edict of primum non nocere.

\section{References}

1. Atlee, W. Spontaneous rupture of an abnormal spleen. Lancet 1932, 1: 291.

2. Rutkav, I.M. Rupture of the spleen in infectious mononucleosis. Arch Surg 1978, 113: 718-720.

3. Cochrane, J.P.S. Infective endocarditis. Br J Hosp Med 1980, 24: $398-404$.

4. Pringle, S.D., McCartney, A.C. \& Cobbe, S.M. Spontaneous splenic rupture as complication of infective endocarditis. Int $J$ Cardiol 1988, 19: 384-386.

5. Atkinson, E. Spontaneous rupture of the spleen. $\mathrm{Br} \mathrm{Med} \mathrm{J}$ 1874, ii: 403. 
6. Orloff, M.J. \& Peskin, G.W. Spontaneous rupture of the normal spleen - a surgical enigma. Surg Gynecol Obstet 1958, 106: 1.

7. Nicoll, J.A.V. Spontaneous rupture of the spleen. Br Med J 1952, 1: 801.

8. Jacobson, S., Ljungdahl, I. \& Lewander, R. Splenic injury due to indirect torsion. J Trauma 1977, 17: 470-473.

9. Lee, D., Anderson, J.R. \& Beanish, D. Adhesions as a primary cause of massive intraperitoneal bleeding. $J R$ Coll Surg Edin 1985, 30: 135-136.

10. Badenoch, D.F., Maurice, H.D. \& Galmore, O.J.A. Spontaneous rupture of a normal spleen. J R Coll Surg Edin 1985, 30: $326-327$.

11. Shee, J.C. Spontaneous rupture of the spleen. Lancet 1972, 2: 604.
12. Bollman, R. \& Bohn, N. Ruptured aneurysm of the splenic artery causing fatal splenic rupture. Beitrage Pathol 1974, 40: 491-493.

13. Bird, D., Kelly, M.J. \& Bird, R.N. Spontaneous rupture of the normal spleen. Br J Surg 1979, 66: 598.

14. Berlinerblace, R., Marmo le Jos, F. \& Bykofsky, M.M. Delayed rupture of the spleen after cardiac massage. JAMA 1980, 243: 364-365.

15. Mearns, A.J. Iatrogenic rupture of the spleen. Br Med J 1973, 1: 395-396.

16. Awad, R.W. Delayed iatrogenic rupture of the spleen. Lancet 1980, ii: 754-755.

17. Telmos, A.J. \& Mittal, V.K. Splenic rupture following colonoscopy. JAMA 1977, 237: 2718.

\title{
Spinal ganglioneuroblastoma-complete response to chemotherapy alone
}

\author{
V. Raina, R. Kamble, R. Tanwar, S.P. Singh and S. Sharma \\ Institute Rotary Cancer Hospital, All India Institute of Medical Sciences, New Delhi 110 029, India
}

Summary: Ganglioneuroblastoma in the spinal region is rare, the treatment of choice being surgical excision. We present a 21 year old male who was diagnosed to have this condition in the dorsolumbar spinal region. The tumour was extending intraspinally and was unresectable. Combination chemotherapy with Adriamycin ${ }^{\circledR}$ (doxorubicin hydrochloride), vincristine, cyclophosphamide, etoposide, ifosfamide and cisplatin resulted in histologically proven complete remission. No radiotherapy or curative resection was done. The patient is alive without evidence of disease 24 months later. Never before has chemotherapy been successfully used as the sole modality of treatment in this condition. Our report raises important questions about the management of this rare condition, particularly in a situation of unresectability.

\section{Introduction}

Neuronal tumours of the central nervous system (CNS) are rare. They are classified as ganglioglioma, ganglioneuroma, ganglioneuroblastoma and neuroblastoma. These related tumours have a common origin from primordial neural crest cells and reflect different maturation patterns of a common neoplasm. Neuroblastoma is the least differentiated containing primitive neuroblasts, ganglioneuroblastoma possesses both primitive neuroblast and ganglion cells, while ganglioneuroma is a fully differentiated form containing mature Schwann cells and ganglion cells. ${ }^{1}$ The

Correspondence: V. Raina, M.D., M.R.C.P. (U.K.), 427 Hawa Singh Block, Asian Games Village Complex, New Delhi 110 049, India.

Accepted: 10 February 1993 treatment of choice for both cerebral and spinal ganglion cell tumours is surgical excision. ${ }^{2,3}$ Radiotherapy is given for residual disease, recurrence or progression. ${ }^{2}$ Although adjuvant chemotherapy has been used in ganglioneuroblastoma with variable results ${ }^{4,5}$ there is no report of the use of chemotherapy as the sole modality of treatment. We report a 21 year old man who achieved complete remission following combination chemotherapy.

\section{Case report}

A 21 year old man was referred to the medical oncology department of this hospital in November 1990. He was earlier admitted to the orthopaedics ward for backache, wasting and weakness of his 